\title{
The Role of Temperament in Cooperation and Level of Anxiety in Preschool and Elementary School Children in the Dental Office
}

\author{
Bahman Seraj ${ }^{1}$, Razieh Khanmohammadi², Shabnam Karami ${ }^{3}$, Fateme Almasi ${ }^{4}$, Mohammad Hassan Hamrah ${ }^{5}$ \\ 12,3,4,5 Department of Paediatric Dentistry, School of Dentistry, Tehran University Medical Sciences, Tehran, Iran.
}

\section{ABSTRACT}

\section{BACKGROUND}

Dental fear and anxiety (DFA) refers to the fear of and anxiety towards going to the dentist. It exists in a considerable proportion of children and adolescents and is a major dilemma in paediatric dental practice. However, temperament has been suggested to be a predictive factor for the child's reaction to dental treatment especially in young ages. This study was done to assess the role of temperament in the levels of anxiety and cooperation in preschool and elementary school children in the dental office.

\section{METHODS}

This descriptive, cross-sectional study evaluated 70 preschools ( 4 - 6 years of age) and elementary school ( 7 - 10 years of age) children presenting to the paediatric dental clinic of TUMS School of Dentistry. The children were generally healthy and had at least one carious primary molar requiring pulp therapy or restorative treatment under local anaesthesia. The temperament trait of children was determined using the Persian version of Malhotra's Temperament Schedule that measures the nine temperament traits identified by Thomas and Chess. Next, the cooperation and level of anxiety in children were determined during anaesthetic injection and cavity preparation using the Venham Clinical Cooperation Scale (VCCS) and Venham Clinical Anxiety Scale (VCAS). Data was analyzed using a regression model.

\section{RESULTS}

The temperament trait of children had a significant correlation with their parent's education level $(\mathrm{P}=0.038)$. Lower sociability scores were significantly correlated with higher level of anxiety and uncooperative behaviour of children during anaesthetic injection and cavity preparation $(\mathrm{P}<0.05)$. Rhythmicity was significantly correlated with anxiety during anaesthetic injection, and higher intensity of response/energy was significantly correlated with poor cooperation of children during injection and higher anxiety during cavity preparation $(\mathrm{P}<0.05)$.

\section{CONCLUSIONS}

Within the limitations of this study, the results of temperament trait can predict the behaviour of children and their level of anxiety and cooperation in the dental office setting.

\section{KEY WORDS}

Anxiety; Cooperation; Child, Preschool; Temperament; Paediatric Dentistry.
Corresponding Author:

Fateme Almasi,

Postgraduate Student,

Department of Paediatric Dentistry,

School of Dentistry,

Tehran University of Medical Sciences,

Tehran, Iran.

E-mail: almasifateme92@gmail.com

DOI: $10.14260 / j e m d s / 2021 / 690$

How to Cite This Article:

Seraj B, Khanmohammadi R, Karami $S$, et al. The role of temperament in cooperation and level of anxiety in preschool and elementary school children in the dental office. J Evolution Med Dent Sci 2021;10(38):3408-3412, $10.14260 /$ jemds/2021/690

Submission 16-05-2021,

Peer Review 31-08-2021,

Acceptance 06-09-2021,

Published 20-09-2021.

Copyright (C) 2021 Bahman Seraj et al. This is an open access article distributed under Creative Commons Attribution License [Attribution 4.0 International (CC BY 4.0)] 


\section{BACKGROUND}

Behavioural control is a common challenge in paediatric dental treatment, which becomes more difficult in the presence of anxiety and pain. ${ }^{1}$ Dental fear and anxiety in children may continue to adulthood and lead to reluctance or avoidance in seeking dental treatment, which can have adverse health consequences. ${ }^{2}$ Anxiety refers to a sense of fear or suppressed desire in response to threats. ${ }^{3}$ According to a review study by Broberg and Klingberg 4 on studies conducted from 1987 to 2006, the prevalence of dental anxiety in 3 to 18 year olds varied from $5.7 \%$ in Denmark to $19 \%$ in Norway. In Brazil, Colares et al. ${ }^{5}$ used dental anxiety questionnaire and reported a prevalence rate of $39.4 \%$ for dental anxiety in children. They also found higher pain expression in children with dental anxiety and those with a previous experience of toothache. ${ }^{5}$

Children have high variations in maturity, personality traits, mood, and emotions, which lead to differences in their cooperation and coping mechanisms in the dental office setting. Thus, certain behavioural measures need to be taken to control the behaviour of children in the dental office.

Assessment of the temperament traits of children may reveal and explain their behavioural, emotional, and social characteristics. ${ }^{6}$ The temperament trait of children can make them susceptible to environmental effects. In other words, temperament is both influenced by and influences the environment. ${ }^{7}$ Thomas and Chess $^{8}$ used the term "goodness of fit" to show the level of agreement between the temperament trait of children and environmental expectations. They also showed that the mismatch between the temperament trait and environmental expectations can lead to behavioural problems.

Thomas and Chess $^{8}$ divided the children into three groups of easy child, slow to warm up child, and difficult child based on their temperament. However, $35 \%$ of children could not be categorized under any category and showed unique temperament properties. The Venham Clinical Cooperation Scale and Venham Clinical Anxiety Scale 9,10 are other scales used for the assessment of behavioural properties and the level of anxiety and uncooperative behaviour of children in the dental office. Both scales have six divisions ( 0 - 5). Higher scores indicate a higher level of anxiety and poorer cooperation. The Venham scale has high reliability between 0.78 and 0.98 ; however, inadequate information regarding its validity is its main drawback. 4

The aetiology of dental fear and dental behaviour management problems have been the topic of many investigations, and some factors such as the general emotional status of the child, dental fear in parents, previous dental experience, and pain experience, have been suggested as the possible etiologies. ${ }^{11}$

For many children, visiting a dentist is a stressful experience due to meeting unfamiliar people, hearing unfamiliar sounds, the unfavourable taste of dental materials, having to lay down on the dental chair, and experiencing discomfort and pain. Poor cooperation and bad reactions of children in the dental office are often due to dental fear, which has been reported in 5 - $20 \%$ of children. ${ }^{12}$ This study aimed to assess the role of temperament in the levels of anxiety and cooperation in preschool and elementary school children in the dental office.
METHODS

This descriptive, cross-sectional study was conducted on 70 preschool (4 - 6 years of age) and elementary school (7 - 10 years of age) children who were selected randomly presenting to the Paediatric Dental Clinic of School of Dentistry, Tehran University of Medical Sciences in 2018. Written informed consent was obtained from all parents prior to the study.

\section{Inclusion Criteria}

1. Age ranges of $4-6$ and $7-10$ years,

2. Complete general health

3. Complete mental health

4. Having parent's informed consent

5. No history of dental treatment and

6. Having at least one carious primary molar tooth requiring anaesthetic injection and restoration or pulp therapy.

\section{Exclusion Criteria}

1. Systemic diseases

2. History of dental treatment ${ }^{13,14}$

3. Patients under 4 years and over 10 years of age and

4. History of psychological disorders. ${ }^{15,16}$

The temperament of children was evaluated using the Persian version of Malhotra's Temperament Schedule ${ }^{17}$ that measures the nine temperament traits identified by Thomas and Chess. ${ }^{8,18}$ The questionnaire was filled out by the mothers and included nine divisions of activity level, rhythmicity, approach/withdrawal, adaptability, the intensity of response (energy), mood, persistence, distractibility, and sensitivity. Next, the levels of anxiety and cooperation of children were determined using the VCCS and VCAS by observing the children's behaviour during anaesthetic injection and cavity preparation (the first 3 min of cavity preparation and caries removal). VCAS and VCCS are 6-point behavioural scales scored 0 - 5 indicative of complete cooperation $(0)$ to no cooperation (5); higher scores indicate a higher level of anxiety or poorer cooperation.

The questionnaire used to collect the information had 45 items related to the daily activities of children. Each item was scored using 5-point Likert scale and assessed the intensity and frequency of occurrence of certain behaviour. Scores 1 and 5 indicated the ultimate frequency of occurrence of certain behaviour. Score 3 indicated moderate behaviour. The acquired total score indicated the temperament trait of children.

The Scoring System of VCAS was as Follows ${ }^{19}$ -

1. Score 0 - Relaxed - smiling, willing, able to converse, displays behaviour desired by the dentist.

2. Score 1 - Uneasy - concerned, may protest briefly to indicate discomfort, hands remain down or partially raised, tense facial expression, high chest, capable of cooperating.

3. Score 2 - Tense - tone of voice, questions, and answers reflect anxiety. During stressful procedures, verbal 
protest, crying, hands tensed and raised but not interfering very much. Protest more, distracting and troublesome. The child still complies with the request to cooperate.

4. Score 3 - Reluctant - pronounced verbal protest, crying. Using hands to try to stop the procedure. Treatment proceeds with difficulty.

5. Score 4 - Interference - general crying, body movements, sometimes needing physical restraints. Protest disrupts the procedure.

6. Score 5 - Out of contact - hard loud swearing, screaming, unable to listen, trying to escape. Physical restraint required.

The Scoring System of VCCS was as Follows ${ }^{9}$ -

1. Score 0 - Total cooperation, best possible working conditions, no crying or physical protest.

2. Score 1 - Mild, soft verbal protest or quiet crying as a signal of discomfort but does not obstruct progress. Appropriate behaviour for the procedure, i.e. slight start at injection, "ow" during drilling if hurting, etc.

3. Score 2 - Protest more prominent. Both crying and hand signals. May move the head around, making it hard to administer treatment. Protest more distracting and troublesome. However, the child still complies with the request to cooperate.

4. Score 3 - Protest presents a real problem to the dentist. Complies with demands reluctantly, requiring extra effort by the dentist. Body movement.

5. Score 4 - Protest disrupts the procedure, requires that all the dentist's attention be directed toward the child's behaviour. Compliance is eventually achieved after considerable effort by the dentist but without much actual restraint (may require holding the child's hands). More prominent body movement.

6. Score 5 - General protest, no compliance or cooperation. Physical restraint is required.

Data was analysed using SPSS version 25 (SPSS Inc., IL, USA), Chi-square. $\mathrm{P}<0.05$ was considered as statistical significance level.

\section{RESULTS}

A total of 70 preschool and elementary school children, including 36 females (51.4\%) and 34 males (48.6\%), participated in this study. Of all, 38 (54.3\%) and 32 (45.7\%) children were pre-schoolers and elementary schoolers aged 4 - 6 and 7 - 10 years, respectively.

Our results indicated a significant difference in the levels of anxiety and cooperation in the two age groups of preschoolers (aged 4 - 6 years) and elementary schoolers (aged 7 - 10 years), with a higher level of anxiety and lower cooperation in younger children. Table 1 presents the frequency distribution of temperament traits based on gender. No significant differences were noted in the frequency distribution of different temperament traits between males and females ( $\mathrm{P}>0.05)$.

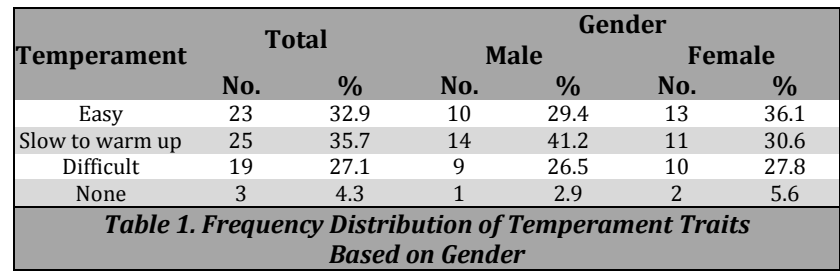

Table 2 represents the mean score of temperament domains acquired by children, indicating that the mean score of all temperament domains was within the normal range.

\begin{tabular}{|ccc|}
\hline Temperament domains & Mean & Std. deviation \\
\hline Sociability & 10.481 & 1.765 \\
Sensitivity & 6.968 & 1.128 \\
Intensity of response/energy & 6.473 & 1.126 \\
Distractibility & 3.453 & 0.899 \\
Rhythmicity & 3.571 & 0.911 \\
\hline Table 2. Mean Scores of Temperament Domains Acquired by Children \\
\hline
\end{tabular}

Table 3 illustrates the frequency distribution of VCAS scores acquired by children during anaesthetic injection and cavity preparation. The results showed that $11.4 \%$ of children had no anxiety during the anaesthetic injection. This rate was $15.7 \%$ during cavity preparation. The remaining children showed variable anxiety levels.

\begin{tabular}{|ccccc|}
\hline VCAS Score & $\begin{array}{c}\text { Anaesthetic Injection } \\
\text { Number }\end{array}$ & $\begin{array}{c}\text { Cavity Preparation } \\
\text { Pumber }\end{array}$ & $\begin{array}{c}\text { Percentage } \\
\text { Numberage }\end{array}$ \\
0 & 8 & 11.4 & 11 & 15.7 \\
1 & 26 & 37.1 & 21 & 30.0 \\
2 & 16 & 22.9 & 19 & 27.1 \\
3 & 11 & 15.7 & 12 & 17.1 \\
4 & 6 & 8.6 & 5 & 7.1 \\
5 & 3 & 4.3 & 2 & 2.9 \\
\hline Table 3. Frequency Distribution of VCAS Scores Acquired by Children \\
during Anaesthetic Injection and Cavity Preparation \\
\hline
\end{tabular}

Table 4 exhibits the frequency distribution of VCCS scores acquired by children during anaesthetic injection and cavity preparation. The results showed that $18.6 \%$ of children cooperated completely during the anaesthetic injection. This rate was $14.3 \%$ during cavity preparation. The remaining children showed variable levels of uncooperative behaviour.

\begin{tabular}{|ccccc|}
\hline VCCS score & $\begin{array}{c}\text { Anaesthetic Injection } \\
\text { Number }\end{array}$ & $\begin{array}{c}\text { Cavity Preparation } \\
\text { Percentage }\end{array}$ & Number & Percentage \\
\hline 0 & 13 & 18.6 & 10 & 14.3 \\
1 & 22 & 31.4 & 21 & 30.0 \\
2 & 17 & 24.3 & 21 & 30.0 \\
3 & 9 & 12.9 & 11 & 15.7 \\
4 & 5 & 7.1 & 4 & 5.7 \\
5 & 4 & 5.7 & 3 & 4.3 \\
\hline Table 4. Frequency Distribution of VCCS Scores Acquired by Children \\
during Anaesthetic Injection and Cavity Preparation \\
\hline
\end{tabular}

The temperament traits had a significant correlation with the education level of parents, and the frequency of children with easy temperament; which was higher among parents with a higher level of education $(\mathrm{P}=0.038)$. There was no significant correlation between the temperament trait and age $(\mathrm{P}=0.858)$ or gender $(\mathrm{P}=0.619)$. Sociability had a significant correlation with the level of anxiety during anaesthetic injection $(\mathrm{P}=0.038)$ and cavity preparation $(\mathrm{P}=$ $0.0003)$. No other significant correlations were noted in this respect $(\mathrm{P}>0.05)$.

Sociability $(\mathrm{P}<0.001)$ and intensity of response/energy $(\mathrm{P}=0.006)$ had significant correlations with the level of cooperation of children during the anaesthetic injection. A significant correlation was also observed between sociability and the level of cooperation of children during the cavity 
preparation $(\mathrm{P}=0.004)$. No other significant correlations were noted $(\mathrm{P}>0.05)$.

In the data analysis, the effect of temperament traits was first assessed on the level of anxiety and cooperation of children by taking into account the effects of age and gender of children and education levels of parents to assess the possible effects of these variables on the results. Next, the effects of age and gender of children and education levels of parents were eliminated to assess the pure effect of temperament traits on the levels of anxiety and cooperation of children. The results showed a significant effect of sociability $(\mathrm{P}=0.009)$ on the level of anxiety during cavity preparation. Moreover, age had significant correlations with cooperation and anxiety during anaesthetic injection and cavity preparation, respectively, and younger children had significantly higher levels of anxiety and uncooperative behaviour $(\mathrm{P}=0.013)$.

The temperament traits had a direct correlation with the level of anxiety $(P=0.040)$ and cooperation $(P=0.013)$ during cavity preparation, and the level of anxiety and uncooperative behaviour increased as the temperament trait shifted to difficult.

\section{DISCUSSION}

This study assessed the role of temperament in the level of anxiety and cooperation in preschool and elementary school children in the dental office using the Persian version of Malhotra's Temperament Schedule, VCCS, and VCAS. The questionnaires were filled out by the mothers because evidence shows that questionnaires filled out by the mothers have high objective validity and can be reliably used for clinical studies. ${ }^{15,16}$ Children with previous dental treatment experience were excluded because a previous dental experience has been reported to be a major cause of dental fear and uncooperative behaviour of children in the dental office. $13,14,20$

In this study, the VCCS and VCAS were selected for data collection because of their easier use than the Frankl scale.21 Moreover, the Venham scales are highly reliable. ${ }^{14}$

The current results revealed that the temperament traits had direct correlation with anxiety and cooperation of children and those with difficult temperaments had significantly lower cooperation and higher anxiety during anaesthetic injection and cavity preparation $(P<0.05)$. Similarly, Su et al.22 observed that uncooperative children in their study mostly had difficult temperaments. Moreover, Aminabadi et al. ${ }^{23}$ found that children with difficult temperaments had significantly higher frequencies of negative behaviours.

The current study showed that sociability had a significant inverse correlation with the anxiety of children during cavity preparation. The intensity of response/energy also had a significant correlation with the anxiety of children during cavity preparation. Sociability and intensity of response/energy were also significantly correlated with the cooperation of children during the anaesthetic injection.

Since the children included in our study had no previous experience of anaesthetic injection or cavity preparation, these were new experiences for them and their reaction to these external painful and stressful stimuli can be correlated with their temperaments. ${ }^{24}$ In our study, children with a higher level of anxiety and lower cooperation had significantly lower sociability scores. Arnrup et al. ${ }^{15}$ observed a significantly higher level of shyness in children with dental fear. Since sociability is somehow opposite to shyness, our results are indirectly in agreement with their findings. On the other hand, children with lower cooperation had significantly lower sociability, which can be due to their lower communication ability. In line with our findings, Su et al.22 showed that uncooperative children had significantly lower adaptability (a subdomain of sociability) than cooperative children. On the other hand, the intensity of response/energy score was significantly higher in children with minimal cooperation and maximal anxiety than the other children during the cavity preparation. This finding can be explained by the fact that highly energetic children cannot sit still in one place and have lower concentration on their acts and subsequently less tolerance. ${ }^{15}$ Furthermore, children with a lower level of anxiety during anaesthetic injection had higher rhythmicity than the others. Similarly, Yang et al. ${ }^{25}$ observed that rhythmicity in children with behavioural management problems was significantly lower than that in other children.

In our study, males and females were not significantly different regarding the level of anxiety and cooperation. The temperament trait had no significant correlation with gender. Su et al. ${ }^{22}$ did not find a significant difference between males and females in dental fear, which is in agreement with our findings. However, Gustafsson et al. ${ }^{16}$ found a significant difference in behavioural scales between males and females, and Klingberg 20 found a higher level of dental anxiety and behavioural problems in females. But Su et al. ${ }^{26}$ assessed the effect of temperament on the behaviour of preschool children and reported that boys had significantly higher risk of behavioural problems than girls. This controversy can be due to the age range of study populations. In our study and that of Su et al..$^{22}$ the evaluation of preschool and elementary school children reveals that gender differences become prominent as the children age and become more sociable. Thus, such differences are not often significant before puberty. ${ }^{15}$

Our study showed significant correlation between the temperaments of children and the education levels of their parents. According to Sprinke, ${ }^{27}$ parents with an educational level below a high-school diploma often have the lowest socioeconomic class, and children raised in such families often have many behavioural problems, such as violence. In addition, the level of education and occupation of parents have significant correlation with the acceptance of children and their social behavior. ${ }^{28}$

Our study also showed significant difference in the level of anxiety and cooperation of the two age groups of preschoolers (4 - 6 years) and elementary schoolers (7 - 10 years), and younger children had higher level of anxiety and lower cooperation. In agreement with our results, Yang et al. ${ }^{25}$ reported that aging decreased the incidence of dental behaviour management problems. Aminabadi et al. ${ }^{23}$ also concluded that younger children had higher frequency of completely negative behaviour than older children.

A relatively small sample size was a limitation of this study. Further studies on larger sample size are required to increase the generalizability of the results. Besides, our study population was derived from the population of children 
referred to the Paediatric Dental Clinic of Tehran University of Medical Sciences; thus, they were not a true representative of the entire population of children. Further, multicentre studies are required to obtain more reliable results.

\section{CONCLUSIONS}

Within the limitations of this study, the results revealed that the temperament traits had significant effects on the level of anxiety and cooperation of children during anaesthetic injection and cavity preparation. It may be concluded that the temperament trait and the sociability, rhythmicity, and intensity of response/energy of children may be used to predict their level of anxiety and cooperation in the dental office setting.

Data sharing statement provided by the authors is available with the full text of this article at jemds.com.

Financial or other competing interests: None.

Disclosure forms provided by the authors are available with the full text of this article at jemds.com.

\section{REFERENCES}

[1] Farokhgisour E, Hashemipour M, Ajdari H. The influence of music on pain sensation and fear in children during dental treatments. J Dent 2008;9(1):93-100.

[2] Skaret E, Raadal M, Berg E, et al. Dental anxiety and dental avoidance among 12 to 18 year olds in Norway. Eur J Oral Sci 1999;107(6):422-8.

[3] Hakeberg M, Berggren U, Gröndahl HG. A radiographic study of dental health in adult patients with dental anxiety. Community Dent Oral Epidemiol 1993;21(1):2730 .

[4] Klingberg G, Broberg AG. Dental fear/ anxiety and dental behaviour management problems in children and adolescents: a review of prevalence and concomitant psychological factors. Int J Paediatr Dent 2007;17(6):391-406.

[5] Colares V, Franca C, Ferreira A, et al. Dental anxiety and dental pain in 5 - to 12 - year - old children in Recife, Brazil. Eur Arch Paediatr Dent 2013;14(1):15-9.

[6] Bates JE. Applications of temperament concepts. New York: John Wiley 1989.

[7] Wachs TD. The nature of nature. Newbury Park, CA, USA: Sage 1992.

[8] Thomas A, Chess S. Temperament and development. New York: Brunner / Mazel Publishers 1977.

[9] Venham LL, Gaulin-Kremer E, Munster E, et al. Interval rating scales for children's dental anxiety and uncooperative behavior. Pediatr Dent 1980;2(3):195202.

[10] Venham LL, Gaulin-Kremer E. A self - report measure of situational anxiety for young children. Pediatr Dent 1979;1(2):91-6.
[11] Klingberg G, Broberg AG. Temperament and child dental fear. Pediatr Dent 1998;20(4):237-43.

[12] Klingberg G, Raadal M, Arnrup K. Dental fear and behavior management problems. Pediatr Dentistry: a Clinical Approach 2009;2:32.

[13] Liddell A, Di Fazio L, Blackwood J, et al. Long-term follow-up of treated dental phobics. Behav Res Ther 1994;32(6):605-10.

[14] Buchanan H, Niven N. Validation of a Facial Image Scale to assess child dental anxiety. Int J Paediatr Dent 2002;12(1):47-52.

[15] Arnrup K, Broberg AG, Berggren U, et al. Lack of cooperation in pediatric dentistry - the role of child personality characteristics. Pediatr Dent 2002;24(2):119-28.

[16] Gustafsson A, Broberg A, Bodin L, et al. Dental behaviour management problems: the role of child personal characteristics. Int J Pediatr Dent 2010;20(4):242-53.

[17] Malhotra S. Manual for Malhotra's Temperament Schedule. Agra: National Psychological Corporation 1988.

[18] Folayan MO, Kolawole KA. A critical appraisal of the use of tools for assessing dental fear in children. Afr J Oral Health 2004;1(1):54-63.

[19] Afshar H, Nakhjavani YB, Mahmoudi-Gharaei J, et al. The effect of parental presence on the 5 year - old children's anxiety and cooperative behavior in the first and second dental visit. Iran J Ped 2011;21(2):193-200.

[20] Klingberg G. Dental fear and behavior management problems in children. A study of measurement, prevalence, concomitant factors and clinical effects. Swed Dent J 1995;103:1-78.

[21] Frankl SN. Should the parent remain with the child in the dental operatory? J Dent Child 1962;29:150-63.

[22] Su JM, Ye XW, Ruan WH, et al. The characteristics of uncooperative children's temperament during dental treatment. Shanghai J Stomatol 2006;15(3):279-81.

[23] Aminabadi NA, Puralibaba F, Erfanparast L, et al. Impact of temperament on child behavior in the dental setting. J Dent Res Dent Clin Dent Prospects 2011;5(4):119-22.

[24] Broberg A, Klingberg G. Child and adolescent psychological development. Pediatr Dent 2009;2:17-31.

[25] Yang C, Zou H, Zou J. Analysis on dental uncooperative behaviors of the first - visit children in clinic. West China J Stomatol 2011;29(5):501-4, 508.

[26] Su J, Ruan W, Ye X, et al. The effects of temperament on behavior in pediatric dentistry of preschool children. Chinese J Appl Psychol 2006;4:379-84.

[27] Sprinkle JE. Domestic violence, gun ownership and parental educational attainment: How do they affect the aggressive beliefs and behaviors of children? Child and Adolescent Social Work Journal 2007;24(2):133-51.

[28] Chen X. Family conditions, parental acceptance and social competence and aggression in Chinese children. Soc Dev 1994;3(3):269-90. 